\title{
Vaginal deliveries in a tertiary centre: a current profile
}

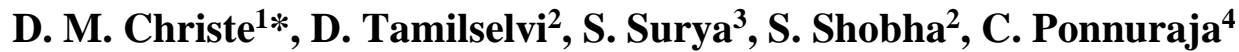

\begin{abstract}
${ }^{1}$ National Institute for Research in Human Reproduction - Field Unit. Indian Council of Medical Research, Institute of Obstetrics and Gynecology, Chennai, Tamil Nadu, India

${ }^{2}$ Department of Obstetrics and Gynecology, Institute of Obstetrics and Gynecology, Chennai, Tamil Nadu, India

${ }^{3}$ Department of Obstetrics and Gynecology, Government Medical College- Omandurar Government Estate, Chennai, Tamil Nadu, India

${ }^{4}$ Department of Statistics, National Institute of Research in Tuberculosis, Chetpet, Chennai, Tamil Nadu, India
\end{abstract}

Received: 28 September 2019

Revised: 11 November 2019

Accepted: 16 November 2019

\author{
*Correspondence: \\ Dr. D. M. Christe, \\ E-mail: drdmchriste@gmail.com
}

Copyright: () the author(s), publisher and licensee Medip Academy. This is an open-access article distributed under the terms of the Creative Commons Attribution Non-Commercial License, which permits unrestricted non-commercial use, distribution, and reproduction in any medium, provided the original work is properly cited.

\begin{abstract}
Background: A normal delivery is what every woman wishes to have. The objective of this study was to find out the maternal and neonatal outcome and background characteristics of women delivering vaginally in a tertiary care center in Chennai, South India.

Methods: For this one-year study, with power above $80 \%$, Parturition records were selected by computerized random numbers, for a calculated sample size. Salient demographic features such as age, residential background and religion were noted. Details of obstetric history, past and current, delivery and baby details and admission to NICU were analyzed. Acceptance of postpartum contraception was noted.

Results: A total of 338 women delivered vaginally. Majority of $63 \%$, were from urban background. Late referrals were $19.2 \%$ of women,38.5\% women had antenatal complications. Primigravida were $49.7 \%$. Nearly $91.4 \%$ of women delivered naturally. Previous pregnancy loss was noted in $14.8 \%$. Term deliveries were in $72 \%$ of women, and $2.7 \%$ of women delivered twins. Average birth weight among primi was $2.5 \mathrm{~kg}$ and in multi it was $2.8 \mathrm{~kg}$. There were no maternal deaths. Perinatal deaths of $2.96 \%$, of which $90 \%$ were preterm births, and all among babies with birth weight below $1.5 \mathrm{~kg}$.

Conclusions: The larger majority of $91.4 \%$ of women had natural vaginal delivery. Primigravida were $49.7 \%$, and $63 \%$ were from urban background. Antenatal complications, obstetric, medical or other complications were noted in $38.5 \%$ of women. Most often observed complications were Gestational hypertension, Gestational diabetes, and Hypothyroidism. NICU care was required for $18 \%$ of babies. Preterm births were $16.6 \%$. Perinatal deaths were seen in $2.96 \%$ of babies. There were no maternal deaths.
\end{abstract}

Keywords: Antenatal complications, Neonatal outcome, Preterm births, Vaginal delivery

\section{INTRODUCTION}

A normal delivery is what every woman wishes to have. The hospital stay, is for a shorter period and the mother is also ambulant and, in a few days after delivery, she is able to carry on some duties of her household which is more acceptable for her and her family. The spouse does not have to stay away from work and lose his daily wages especially in lower socio-economic groups which form the major part of our population. The shorter hospital stay, also poses lesser cost for both the family and the government. The pain and the minimal trauma to the birth passage of the women, in natural delivery is transient and heals quickly. More important is the long-term effects seen in the family which is of greater concern which is stated by sociologists. Increasing caesarean section rates 
are a matter of concern in many countries - $17.2 \%$ in India, 34\% in Tamil Nadu (NFHS-4, 2015-16). Caesarean section rates higher than $10 \%$ are not associated with reductions in maternal and new-born mortality rates. Every effort should be taken to provide intrapartum support to the birthing woman, for a positive birthing experience. $^{1}$ The WHO 2018, human reproduction program, mentions that many women have fear and anxiety during labor which precipitates complications. Though every effort should be made to provide caesarean section to a woman in need, rather than striving to achieve a specific rate, studies state that women are three times more likely to die during Caesarean delivery than a vaginal birth, and what remains true is that once a woman has had her first C-section, she is more likely to have a Csection in her future deliveries. ${ }^{2,3}$ It is essential that health care providers provide continuous support to the mother during childbirth to enable her to have a natural delivery. ${ }^{4}$ Tertiary referral centers have obstetric admissions with numerous obstetric and medical complications. ${ }^{5} \mathrm{We}$ sought to find out the outcome of mother and baby and background features among women delivering vaginally, in a referral centre where more women with complications are admitted for safe confinement. Objective of this study was to find out the maternal and neonatal outcome and background characteristics of women delivering vaginally in a tertiary care center in Chennai, South India.

\section{METHODS}

Tertiary referral center in Chennai, Tamil Nadu, India. This is a retrospective analytical study. This analytical study was conducted using data from the 2017 parturition data from registers. The sample size was calculated for a study power of $80 \%$, within confidence interval limit of 95. Approval for conducting this study was given by the institutional ethics committee. Consent was not obtained from individual study participants as data was accessed from Medical records section only and was analyzed maintaining complete patient confidentiality. Tertiary referral centers have admissions with numerous obstetric and medical complications. Majority of women are referred quite often late. We analyzed the parturition data of women delivering by vaginal route, to find out maternal and perinatal outcome. Selection of case records: The data from case sheets of pregnant women admitted for obstetric care in, our tertiary care centre were scrutinized. The study period was the calendar year 2017, starting from January $1^{\text {st }}$ and ending on $31^{\text {st }}$ of December 2017. The sample size was calculated for a power of $80 \%$, and within a $95 \%$ limit confidence interval. Statistical analysis was done by using SPSS software. Parturition records were accessed by selection of case records for the sample size. To establish an appropriate selection, the dates of delivery of women, whose case records were selected for inclusion in the study, were the first and second dates of each month, of all twelve months of the year. This was to reduce statistical errors and for obtaining relevant values for the tests of significance. The inclusion criteria were selection of all parturition records, of women, where delivery was conducted by vaginal route, on the selected dates. Natural vaginal delivery with and without episiotomy. Vaginal delivery by forceps, of outlet, low mid cavity, and vacuum assisted, deliveries. Assisted breech deliveries delivered vaginally were included. The parturition records, of all other mode of deliveries, conducted, on the same days were excluded.

Demographic features, obstetric history, gestational age and antenatal complications were recorded. Maternal outcome and baby details including sex of the baby, birth weight, APGAR and admission to new born intensive care unit (NICU) were analyzed. The acceptance of postpartum contraception by the birthing women was noted.

\section{RESULTS}

In the study group, 338 women delivered vaginally. The majority of women belonged to the age group of 20-25 years, $(58 \%)$ and a large number of 212 women forming $63 \%$ of the study group were from an urban background. 65 women were referred late to the center. Many of the women $78.1 \%(n=264)$ delivered at term (Figure 1$)$.

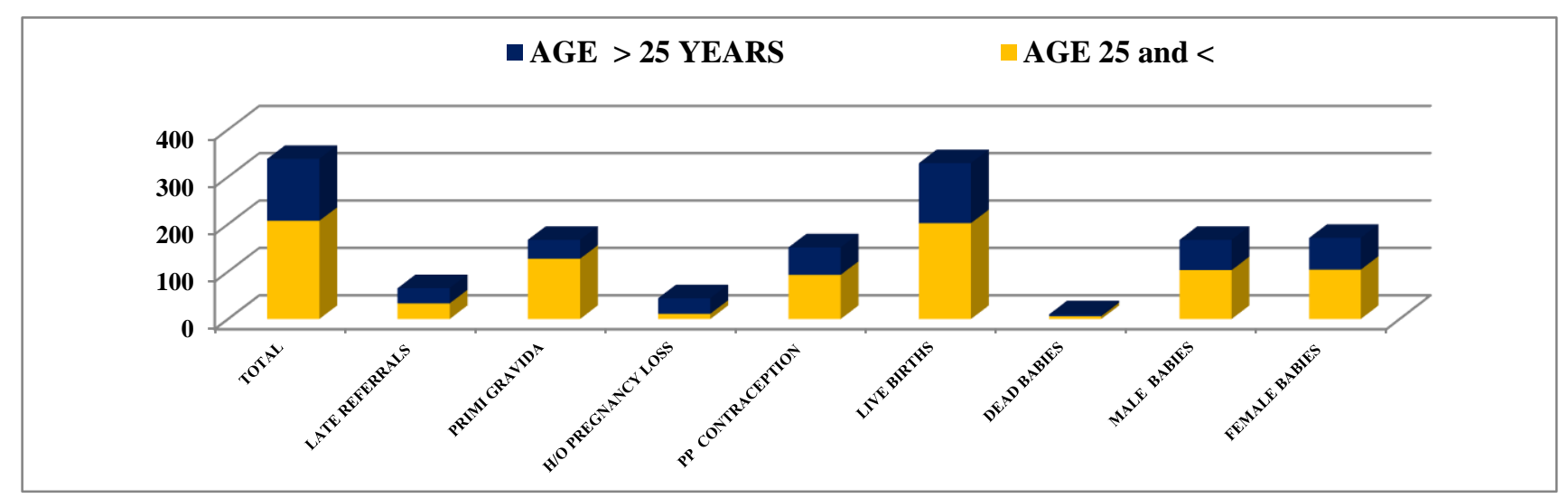

Figure 1: Vaginal births - maternal background and neonatal outcome. 
The majority of $58 \%$ women belonged to the age group of 20-25 years, and a large number of $63 \%$ of the study group of women were from an urban background. Late referrals were $19.2 \%$ of women. PP Contraception accepted by $44.6 \%$ of women.

Twenty-two women required assistance for delivery with forceps or vacuum extraction and three were delivered as breech extraction. $8.6 \%$ deliveries were labor natural with episiotomy, $5.9 \%$ forceps, $0.8 \%$ breech extraction and $0.7 \%$ vacuum delivery. The larger majority of $91.4 \%$ of women $(\mathrm{n}=309)$ who had vaginal deliveries had a natural delivery and only a small number of 29 of these women required episiotomy. The gestational age (GA) of $75.4 \%$ of babies at birth was 34 weeks or above.

Multi gravid women formed a marginally larger majority of ( $n=172$ women) $50.9 \%$ of the study group women. Of these, a small number of $1.2 \%(n=4)$ of the study group were grand multis.

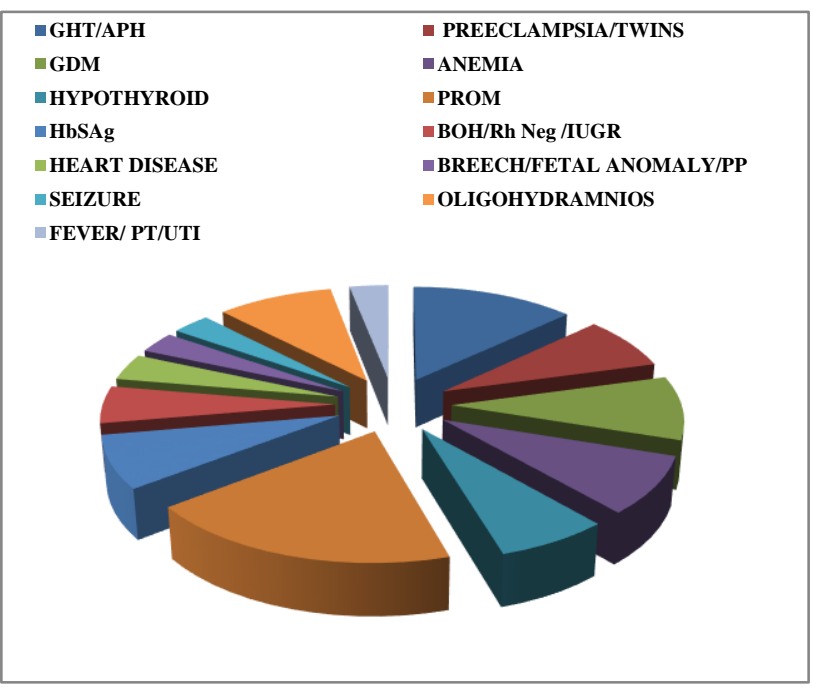

Figure 2: Antenatal complications in women.

Antenatal complications, medical obstetric and fetal complications were present in $38.5 \%$ of women, in the study group. Most often seen complications were gestational hypertension, and preeclampsia gestational diabetes, anemia and hypothyroidism.

Nearly $38.5 \%(n=130)$ of the total group of women in the study had antenatal complications, medical or obstetric including fetal complications (Figure 2). The most often observed complications were Gestational hypertension, Gestational diabetes, and hypothyroidism. Nearly $3 \%$ of antenatal complications and forming $8 \%$ of the total study group of women were positive for HBsAg.

Pregnancy complications of premature rupture of membranes constituted a significant $19.2 \%$ of antenatal complications and observed in $7.4 \%$ of the study group of women who had vaginal delivery. The second commonly noted obstetric complication was multiple pregnancy of

twin pregnancy and recorded in $6.2 \%$ of the antenatal complications and occurred in $2.1 \%$ of the study group of vaginal deliveries. Pregnancy loss in the past obstetric history was noted in $14.8 \%$ of $(n=49)$ women. The two genders were almost equal in number, but there were more perinatal deaths among male babies. There were twice the number of low birth weight babies in the younger age group of women. The birth weight range for Term babies was 0.96 to $4.5 \mathrm{~kg}$. Preterm babies constituted $16.6 \%(n=55)$ of the total number of babies in the study group. A smaller number of $44 \%$ of preterm babies were females and male babies formed $56 \%$ of the preterm group (Figure 3, Figure 4). There were no maternal deaths in the study group of women.

AGE > 25 YEARS AGE 25 YEARS and <

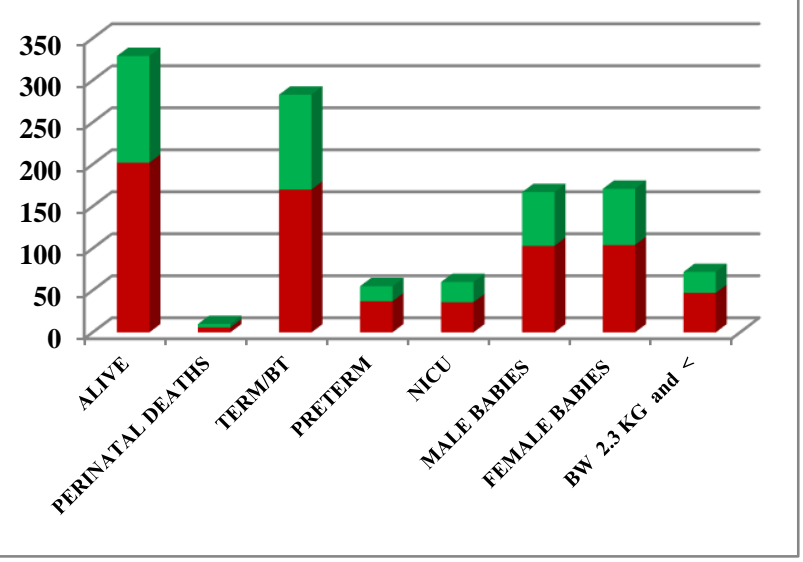

Figure 3: Vaginal births - neonatal outcome.

Nearly $97.3 \%$ of babies were born alive. $83.7 \%$ babies were term/ near term. Male and female babies were almost equal in number. NICU admission was required for $17.8 \%$ of babies. For comparison of neonatal outcome, we divided the total study population of mothers who delivered vaginally into two groups. Group I, with 207 women aged 25 years and below. Group II, with 131 women, aged 26 years and above. There were 202 live births and five babies were dead born and one baby died after birth. The two genders were almost equal in number. Male babies were 102 in number and Female babies numbered 103. As based on neonatologist's opinion, of survival of babies based on gestational age at birth we sought to group babies as term or borderline term if the baby was born after completing 34 weeks of gestation. A large number of 170 babies were born at term or near term. A smaller number of 37 babies were born preterm, before completing 34 weeks of gestation. A significant number of 47 babies had a birth weight of less than $2.3 \mathrm{~kg}$. NICU admission was necessary for 36 babies. The graph shows the curve of distribution of birth weight of term and preterm babies. The birth weight range for Term babies was 0.96 to $4.5 \mathrm{~kg}$ and Preterm babies the birth weight range was 0.56 to $3.2 \mathrm{~kg}$. 


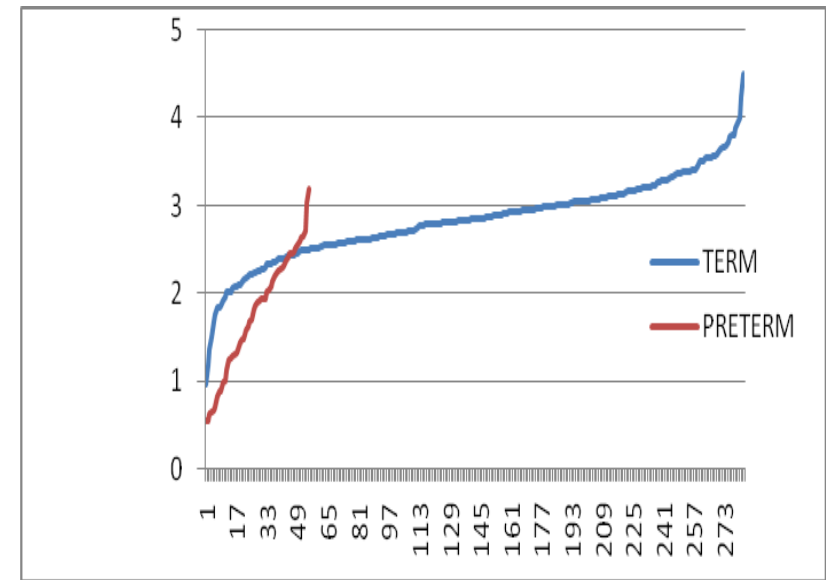

Figure 4: Birth weight of term and preterm babies.

\section{Perinatal mortality}

There were ten perinatal deaths. Nine were dead born and one baby died soon after birth. The age of mothers ranged from 21 to 39 years. The birth weight of all the babies was below $1.5 \mathrm{~kg}$ and the range of birth weight was from 0.63 to $1.49 \mathrm{~kg}$. The causes of perinatal deaths were associated antenatal medical or obstetric complications (Figure 5, Figure 6) in the mother or fetal anomalies. All ten Perinatal deaths were recorded in babies born to women with ante natal complications. Majority of mothers were primis. Nearly $70 \%$ of mothers hailed from urban areas, and half the number of perinatal deaths were in babies with birth-weight one $\mathrm{kg}$ and less. Male babies formed $70 \%$ and $90 \%$ of babies were born preterm (Figure 5, Figure 6).

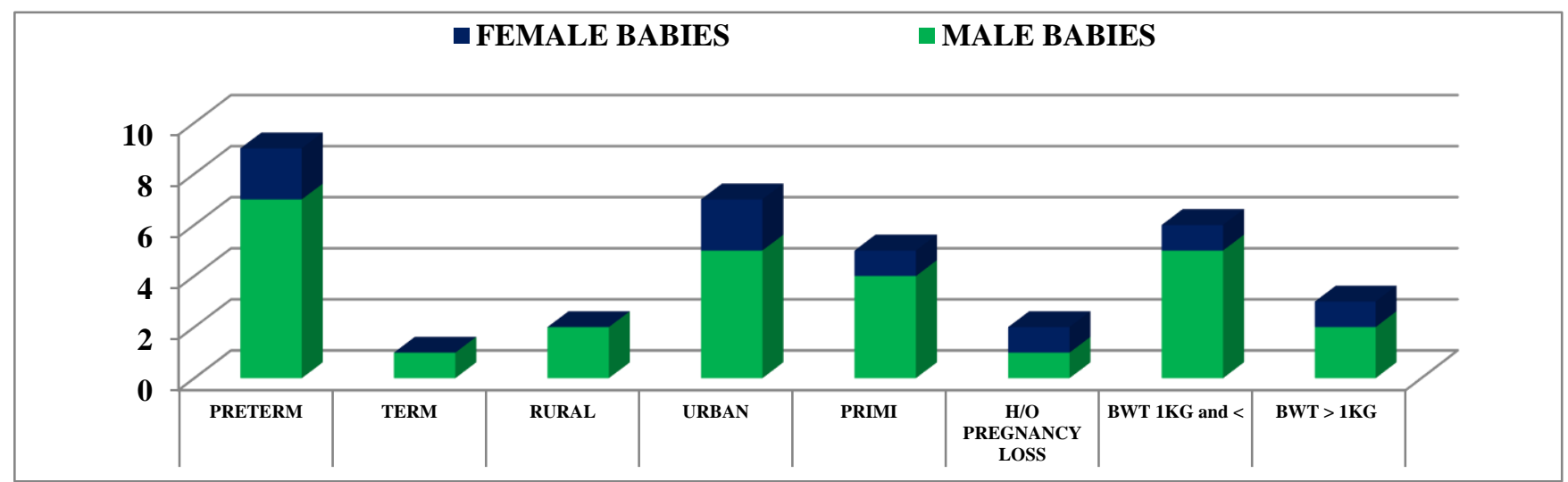

Figure 5: Perinatal mortality.

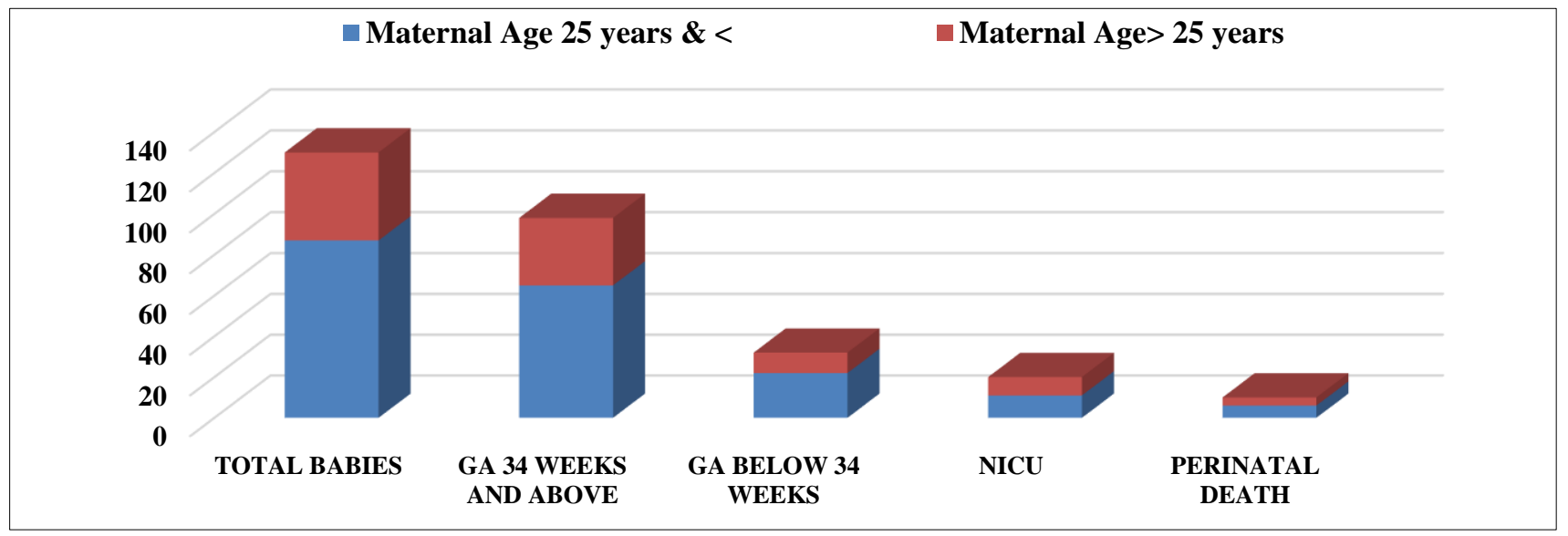

Figure 6: Neonatal outcome in women with ante natal complications.

Nearly $70 \%$ of mothers hailed from urban areas, and half the number of perinatal deaths were in babies with birthweight one $\mathrm{kg}$ and less. Male babies formed $70 \%$ and $90 \%$ of babies were born preterm. The age of mothers was between 21 years to 39 years. Birth weight range was from 0.63 to $1.49 \mathrm{~kg}$. The principal antenatal complications encountered in mothers of still born babies were Multiple pregnancy with prematurity, severe IUGR, fetal anomalies and anemia. Perinatal mortality was more among male babies.

Antenatal complications, obstetric, medical or other complications were noted in $38.5 \%$ of the study group. The majority of $67 \%$ of women with AN complication 
were aged 25 years or below. The GA of $75.4 \%$ of babies at birth was 34 weeks or above (Term/Borderline Term). Twenty babies born to women in the group of women with antenatal complications, forming $18.5 \%$ of the total no. of babies born, required NICU admission. All ten Perinatal deaths were recorded in babies born to women in this group, of women with antenatal complications.

\section{DISCUSSION}

The age group of women who delivered by the vaginal route, ranged from 16 years to 40 years. Teenage pregnancy was recorded in $3.6 \%$ of women.6 The majority of women who delivered vaginally belonged to the age group of $20-25$ years, 6 and $63 \%$ of the study group were from an urban background. Nearly $19.2 \%$ of women were referred late to the hospital for delivery. Among the babies born, the two genders, of males and females were almost equal in number. The number of preterm babies born to younger group of women was twice that of the number born to older women $(n=18)$ aged above 25 years.

Antenatal (AN) complications were present in $38.5 \%$ of women in the study group. ${ }^{7}$ Twenty- two women required assistance for delivery with forceps or by vacuum extraction. ${ }^{8}$ Nearly $49.7 \%$ of women were primigravid. ${ }^{9}$ A significant number of women forming $2.1 \%$ of the total group had complicating hypothyroidism. ${ }^{10-12} \mathrm{HBsAg}$ test was positive in a significant number of $8 \%$ of the study group of women. ${ }^{13,14}$ A significant number of women forming $1.8 \%$ of the total group, who were positive for HBsAg, had an additional complication of gestational diabetes.

There were four women with a past history of single pregnancy loss, and among this group of women three women delivered preterm babies. Nearly 15 primiparous women gave a past history of pregnancy loss. Nearly $2.1 \%(n=7)$ of the total group of women who delivered vaginally $(n=7)$ gave a past history of two or more [ higher order] abortions. It was significant to note that all seven women in this group, delivered alive and healthy babies, only one baby was border line preterm, and all had at birth APGAR scores of 8 and above, and also important to note that none of the babies born to women in this group, required admission in NICU. It was a noticeable feature that the birth weight of babies born to this group of women was in the range from 2.4 to $3.3 \mathrm{~kg}$.

Twenty babies born to women in this group of women with antenatal complications required NICU admission. All ten perinatal deaths, were recorded in babies born to women in this group. A significant number of 25 babies weighed less than $2.3 \mathrm{~kg}$. NICU admission was necessary for 24 babies 15,16 . The survival rate of babies was good because $84 \%$ of babies were born after completing at least 34 weeks of gestation. ${ }^{15,16}$ Though the total number of babies included male and female babies almost equal in number there were more perinatal deaths among male babies. ${ }^{15-17}$ A large group of $67 \%$ of women with AN complications was in the age group of 25 years or below. ${ }^{18,19}$

The majority and forming $70.4 \%$ of the total number of babies born in the study group were AGA babies weighing $2500 \mathrm{gm}$ to $3500 \mathrm{gm}$, and a very small number were LGA babies. ${ }^{20,21}$ A smaller number of $44 \%$ of preterm babies were females and male babies formed $56 \%$ of the preterm group. ${ }^{22}$

\section{CONCLUSION}

Multi gravid women, formed a marginal majority of $50.3 \%$ of the study group women. The age group of women ranged from 16 years to 40 years. Majority of $58 \%$ of women were younger and aged 25 years or below, and a large number forming $63 \%$ of the study group were from an urban background. Term (including near term) deliveries was noted in $78.1 \%$ of the women, though $18.3 \%$ of women were referred late to the hospital for delivery. The birth weight range for Term babies was 0.96 to $4.5 \mathrm{~kg}$ and for Preterm babies, it was 0.56 to 3.2 $\mathrm{kg}$. Admission and care in NICU were necessary for $17.8 \%$ of the total group of babies born. Preterm babies formed $16.3 \%$ of the total number of babies in the study group. Perinatal mortality rate was $2.96 \%$ and all were among babies with a, birth weight below $1.5 \mathrm{~kg}$, and $90 \%$ of still births were preterm. There were more perinatal deaths among male babies.

The maternal outcome showed that the larger majority of $91.4 \%$ of women who had vaginal deliveries had natural delivery though nearly $38.5 \%$ of women had antenatal complications, of gestational hypertension, and preeclampsia, gestational diabetes, Anemia and hypothyroidism, and good outcome in mother and baby was seen in $14.8 \%$ of women with a past history of pregnancy loss. The study results showed that despite antenatal complications, good outcome in mother and baby was evident in vaginal delivery. It is essential that every possible effort should be made by health care providers at all levels, to lend active support and encouragement for the birthing woman to realize safe vaginal delivery.

\section{ACKNOWLEDGMENTS}

Authors would like to thank all the staff, of the centre who lent their support in preparing this article.

\section{Funding: No funding sources \\ Conflict of interest: None declared \\ Ethical approval: The study was approved by the Institutional Ethics Committee}

\section{REFERENCES}

1. WHO recommendations: intrapartum care for a positive childbirth experience. Geneva: World Health 
Organization; 2018. Available at: https://www.who.int/reproductivehealth/intrapartumcare/en/ Accessed on $29^{\text {th }}$ October 2019.

2. Christe DM, Shaanthy TK, Gunasingh. Delivery by repeat caesarean section today: an overview. Int $\mathbf{J}$ Reprod Contracept Obstet Gynecol. 2018;7(10):4127-32.

3. Keag OE, Norman JE, Stock SJ. Long-term risks and benefits associated with cesarean delivery for mother, baby, and subsequent pregnancies: Systematic review and meta-analysis. PLoS Med. 2018;15(1):e1002494.

4. Rahnama P, Mohammadi K, Montazeri A. Salient beliefs towards vaginal delivery in pregnant women: A qualitative study from Iran BMC. Repro Health. 2016;13:7.

5. Pacagnella RC, Cecatti JG, Parpinelli MA. Delays in receiving obstetric care and poor maternal outcomes: results from a national multicentre cross-sectional study. BMC Preg Childbirth. 2014;14:159.

6. Cavazos-Rehg PA, Krauss MJ, Spitznagel EL. Maternal age and risk of labor and delivery complications. Matern Child Health J. 2015;19(6):1202-11.

7. Jeon J, Sunghun Na. Vacuum extraction vaginal delivery: current trend and safety. Obstet Gynecol Sci. 2017;60(6):499-505.

8. Anggondowati T, El-Mohandes AE, Qomariyah SN. Maternal characteristics and obstetrical complications impact neonatal outcomes in Indonesia: a prospective study. BMC Preg Childbirth. 2017;17:100.

9. Al-Shaikh GK, Ibrahim GH, Fayed AA, Al-Mandeel H. Grand multiparity and the possible risk of adverse maternal and neonatal outcomes: a dilemma to be deciphered. BMC Pregn Childbirth. 2017;17(1):310.

10. Sim WH, Araujo Júnior E, Da Silva Costa F, Sheehan PM. Maternal and neonatal outcomes following expectant management of preterm prelabour rupture of membranes before viability. J Perinat Med. 2017;45(1):29-44.

11. Thiruvikrama Prakash G, Das AK, Habeebullah S, Bhat V, Shamanna SB. Maternal and neonatal outcome in mothers with gestational diabetes mellitus. Indian $\mathbf{J}$ Endocrinol Metab. 2017;21(6):854-8.

12. Domanski G, Lange AE, Ittermann T, Allenberg H, Spoo RA, Zygmunt M, et al. Evaluation of neonatal and maternal morbidity in mothers with gestational diabetes: a population-based study. BMC Preg Childbirth. 2018;18(1):367.

13. Tamilselvi D, Tamilselvi N, Shoba S, Krishnamoorthy J, Christe DM. To prevent jaundice in pregnancy today. $\mathrm{J}$ Pharm Biomed Sci. 2017;07(3):72-6.

14. Mishra S, Purandre P, Thakur R, Agrawal S, Alwani M. Study on prevalence of hepatitis B in pregnant women and its effect on maternal and fetal outcome at tertiary care centre. Int $\mathbf{J}$ Reprod Contracept Obstet Gynecol. 2017;6(6):2238.

15. Sasireka BI, Christe DM, Baby Vasumathi S. Survival outcome of infants in NICU a three year review. JMSCR. 2015;3(9):7614-19.

16. Sasireka BI, Christe DM, Prabu RS, Vasumathi SB. Recent Advances in NICU in a referral centre. JPOG 2015;6(4):109-15.

17. Gluck O, Tairy D, Bar J, Barda G. The impact of mode of delivery on neonatal outcome in preterm births. J Matern Fetal Neonatal Med. 2019;1-7.

18. Li Y, Tian Y, Liu N, Chen Y, Wu F. Analysis of 62 placental abruption cases: risk factors and clinical outcomes. Taiwan J Obstet Gynecol. 2019;58(2):223-6.

19. Sehgal R, Kriplani A, Vanamail P, Maiti L, Kandpal $\mathrm{S}$, Kumar N. Assessment and comparison of pregnancy outcome among anaemic and non anaemic primigravida mothers. Indian $\mathbf{J}$ Public Health. 2016;60(3):188-94.

20. Kolluru V, Harika R, Kaul R. Maternal and perinatal outcome associated with pregnancy induced hypertension. Int $\mathbf{J}$ Reprod Contracept Obstet Gynecol. 2016;3367-71.

21. Gupta T, Gupta N, Jain J, Gupta S, Bhatia P, Bagla J. Maternal and perinatal outcome in patients with severe pre-eclampsia/ eclampsia with and without HELLP syndrome. J Univers Coll Med Sci. 2014;1(4):7-12.

22. Sharma D, Dixit PV, Gavit Y. Maternal and perinatal outcome in hypothyroidism in pregnancy: a prospective observational study. Int $\mathbf{J}$ Reprod Contracept Obstet Gynecol. 2017;6(12):5548.

Cite this article as: Christe DM, Tamilselvi D, Surya S, Shobha S, Ponnuraja C. Vaginal deliveries in a tertiary centre: a current profile. Int J Reprod Contracept Obstet Gynecol 2020;9:134-9. 